\title{
artigo

\section{Aleitamento materno: o desafio da mãe trabalhadora que amamenta em uma sociedade capitalista}

\author{
Breastfeeding: the challenge of the working mother who breastfeeds in a capitalist society \\ Lactancia materna: el desafío de la madre trabajadora que amamanta en una sociedad capitalista
}

\begin{abstract}
RESUMO
$\mathrm{O}$ artigo discorre sobre os desafios e enfrentamentos impostos à mulher trabalhadora, mãe, que deseja amamentar seu bebê em uma Sociedade Capitalista. 0 método de pesquisa realizado foi o estudo bibliográfico de aporte qualitativo, no período de julho e agosto de 2020. A busca do material utilizado para fundamentar ao estudo foi através da base de dados do SciELO, Rev. Saúde Pública e em marcos normativos sobre o tema "Amamentação" publicados em português entre os anos de 1997 a 2017. Os resultados apontam que os empregadores que respeitam as Leis que beneficiam as mães trabalhadoras, oferecem a elas local apropriado para a guarda de seus bebês e facilitam a amamentação de seus filhos no local de trabalho, contam com funcionárias que apresentam menor número de faltas, demonstram maior interesse em desenvolver suas atividades e apresentam como resultado, maior índice de produtividade, pois não precisam se preocupar com seus bebês doentes.
\end{abstract}

DESCRITORES: Aleitamento materno; Mulher trabalhadora; Responsabilidade Social; Sociedade Capitalista.

\section{ABSTRACT}

The article discusses the challenges and confrontations imposed on the working woman, mother, who wants to breastfeed her baby in a Capitalist Society. The research method carried out was the bibliographic study of qualitative contribution, in the period of July and August 2020. The search for the material used to support the study was through the database of SciELO, Rev. Saúde Pública and in normative frameworks on the "Breastfeeding" theme published in Portuguese between 1997 and 2017. The results indicate that employers who respect the Laws that benefit working mothers, offer them an appropriate place for the custody of their babies and facilitate the breastfeeding of their children in the workplace, have employees who have fewer absences, show greater interest in developing their activities and have, as a result, a higher productivity index, as they do not have to worry about their sick babies.

DESCRIPTORS: Breastfeeding; Working woman; Social responsability; Capitalist society.

\section{RESUMEN}

El artículo analiza los desafíos y enfrentamientos que se le imponen a la mujer trabajadora, madre, que quiere amamantar a su bebé en una Sociedad Capitalista. El método de investigación realizado fue el estudio bibliográfico de aportación cualitativa, en el período de julio y agosto de 2020. La búsqueda del material utilizado para sustentar el estudio fue a través de la base de datos de SciELO, Rev. Saúde Pública y en marcos normativos sobre la Tema "Lactancia Materna" publicado en portugués entre 1997 y 2017. Los resultados indican que los empleadores que respetan las Leyes que benefician a las madres trabajadoras, les ofrecen un lugar adecuado para la custodia de sus bebés y facilitan la lactancia materna de sus hijos en el lugar de trabajo, tienen empleados que tienen menos ausencias, muestran mayor interés en desarrollar sus actividades y tienen, como resultado, un mayor índice de productividad, ya que no tienen que preocuparse por sus bebés enfermos.

DESCRIPTORES: Amamantamiento; Mujer trabajadora; Responsabilidad social; Sociedad capitalista.

RECEBIDO EM: 17/08/2020 APROVADO EM: 28/09/2020

\section{Jozadake Petry Fausto Vitorino}

Assistente Social pela Universidade Federal de Santa Catarina (UFSC) e especialista em Políticas Sociais Integradas pela Universidade Estácio de Sá (Florianópolis/SC). Pós-graduanda em Saúde Pública pela Universidade EducaMais (São Paulo). Técnica de Enfermagem, especialização técnica em Enfermagem do Trabalho e Instrumentação Cirúrgica. Membro do Núcleo de Estudos da Criança, Adolescente e Família (NECAD/UFSC).

ORCID: 0000-0001-5656-3337 


\section{INTRODUÇÃO}

$\mathbf{N}$ a contemporaneidade, o desempenho e a contribuição da mulher e mãe, inserida na sociedade capitalista, já é fato notadamente comprovado com relação aos benefícios voltados para o crescimento, desenvolvimento econômico e social de nosso país. No entanto, a mulher, mãe que amamenta o seu bebê é levada a desmamar precocemente, pois se vê obrigada a exercer suas atividades de trabalho fora de seu lar, principalmente as que vivem em centros urbanos, devido à precariedade nas condições de transporte e ainda, à distância percorrida entre a casa e o seu local de trabalho. ${ }^{1}$

Todavia, cabe ressaltar que o aleitamento materno exclusivo do recém-nascido até os seis meses de idade, é muito importante. O fato é amplamente reconhecido pela Organização Mundial da Saúde (OMS) Instituições e órgãos não-governamentais que estudam e divulgam assuntos relacionados à amamentação são unânimes em afirmar que, no primeiro ano de vida do bebê, a amamentação é essencial, entretanto, deve estender-se preferencialmente, até a criança completar dois anos ou mais de vida. ${ }^{2}$

Amamentar, além de trazer benefícios à saúde da criança, por diminuir o aparecimento de patologias, diminui também os gastos financeiros da família e ainda traz benefícios econômicos às empresas, pois reduz a ausência de mães trabalhadoras ao trabalho. ${ }^{3}$

Nesse sentido, é preciso lembrar que no art. 396 da Consolidação das Leis do Trabalho - CLT, assegura que as mães que querem alimentar o seu filho, até 1 ano completo de idade, têm o seguinte direito: "a mulher terá direito, durante a jornada de trabalho, a 2 (dois) descansos especiais, de meia hora cada um (...)" ${ }^{4}$ Todavia, no “ $\$ 1^{\circ}$ do art. 389 , essa obrigatoriedade só se aplica aos estabelecimentos em que trabalhem pelo menos trinta mulheres com mais de dezesseis anos de idade, o que já isenta uma grande parte das empresas". 5

Com efeito, o ideal e desejável seria que todas as mães pudessem amamentar os seus bebês até os seis meses de vida, sem interrupção, mas sabemos que nem sempre isso é possível. As mães trabalhadoras, que moram longe do seu trabalho e que não têm apoio de nenhum familiar para levar o bebê até o seu ambiente de trabalho, necessitam deixar os seus filhos em creches ou com alguém da sua confiança e, assim, substituem a amamentação materna pela mamadeira, bicos e demais alimentos. ${ }^{6}$

As empresas que não incentivam ou apoiam as mulheres trabalhadoras deixando de oferecer a elas condições de continuar com a amamentação, prejudicam tanto da saúde da mãe quanto a do bebê, e, como resultado, observa-se prejuízos econômicos e financeiros a todas as partes envolvidas, uma vez que a família, o Estado e as empresas devem assumir sua responsabilidade social. ${ }^{7}$

Diante do exposto, a questão central a ser problematizada é: Quais os enfrentamentos e desafios da mulher trabalhadora, mãe, e quer amamentar o seu filho(a) em uma sociedade capitalista?

\section{MÉTOdO}

Trata-se de um breve estudo bibliográfico de aporte qualitativo, realizado no período de julho e agosto de 2020. A busca do material utilizado para fundamentar e dar suporte ao estudo foi através da base de dados do SciELO, Rev. Saúde Pública e em marcos normativos sobre o tema "Amamentação" publicados em idioma português entre os anos de 1997 a 2017.

Para Gil (2002), a pesquisa se caracteriza como bibliográfica por haver um estudo de casos, que podem ser definidos pela busca de materiais confiáveis, como: artigos e livros que já foram produzidos pela comunidade científica. ${ }^{8}$

Richardson (2008) diz que os estudos qualitativos podem descrever a complexidade de determinado problema, analisar a interação de determinadas variáveis, compreender e classificar processos dinâmicos vividos por grupos sociais, contribuir no processo de mudança de determinado grupo e possibilitar o entendimento das particularidades do comportamento dos indivíduos e dos detentores dos meios de produção - que trabalham nas empresas. ${ }^{9}$

É importante salientar que a escolha pelo método bibliográfico e qualitativo facilita a busca do aporte pelo pesquisador, entretanto, torna-se um desafio, pois a escolha do material pode garantir ou não o sucesso da pesquisa.

\section{A importância do aleitamento materno}

O leite materno é o melhor alimento que o bebê pode receber. É rico em nutrientes, de rápida digestão e proporciona o crescimento e desenvolvimento sadio, além de resguardar o bebê contra diversos tipos de doenças. Mesmo que a mãe amamente em ambientes úmidos ou secos, o leite materno provê todas as vitaminas de líquido que o bebê necessita.

Entretanto, a gestante precisa se alimentar bem e estimular o bico do seio durante toda a gestação, e assim, terá todas as condições para realizar a amamentação, todavia, para isso aconteça, ela precisa receber orientação durante o pré-natal.

As responsabilidades são muitas, devido ao compromisso da amamentação, e isso dificulta para as mães se ausentar por longas horas ou dias, pois se deixar de amamentar por um longo período, a produção do leite deixa de ser estimulada e aos poucos o leite vai desaparecendo. Evidentemente, isso depende de cada caso, pois cada organismo reage de maneira diferente, por isso, amamentar exige responsabilidade e continuidade.

Contudo, as recompensas são valiosas, isso quando a mãe consegue ter alcance da dimensão da herança preciosa que ela deixa para o seu filho(a) através de seu leite. É de fato o alimento mais puro e rico de afeto que necessitamos ao longo de nossas vidas.

As mães que amamentam veem seus bebês crescerem com menos riscos de terem alergias, e elas, por sua vez, têm menos chances de desenvolver a obesidade, colesterol alto, diferentes tipos de diabetes e hipertensão arterial. Ainda previne o câncer de mama e fortalece a relação entre a mãe e o bebê, sem que seja necessário o uso de bico para acalmar o bebê.

Logo, é comum vermos mães utilizan- 
do o bico para acalmar a criança, o bico torna-se, um "cala-boca" que acalma e o bebê dorme. Entretanto, utilizar bico para esses fins é prejudicial para o desenvolvimento correto da mandíbula. Bebês que chupam bico têm mais tendência a utilizar aparelho ortodôntico.

E, além de todos esses aspectos de saúde, a amamentação estabelece o vínculo afetivo puro e de trocas imensuráveis de amor verdadeiro entre a mãe e seu filho. Além disso, todas as mães, seja no trabalho, em sua casa ou em outros espaços, têm o direito de amamentar o seu bebê, sem serem interrompidas ou constrangidas por esse ato. Todas, sem exceção, devem ser respeitadas, auxiliadas e incentivadas a amamentar. E para que se sintam seguras e confortáveis merecem receber todas as informações sobre o aleitamento materno. A informação estimula e incentiva a mulher a querer amamentar. Além disso, torna essa experiência mais planejada, desejada, tranquila e prazerosa.

\section{Direito das puérperas à amamentação}

A Lei $n^{\circ}$ 13.436/2017 (BRASIL, $2017)^{10}$ determina que todas as parturientes têm o direito em receber acompanhamento técnico especializado sobre a amamentação enquanto estiverem na unidade hospitalar. Essas orientações são fundamentais, principalmente para as mães que estão passando pela primeira gestação, pois, muitas por vezes, se sentem inseguras, e têm medo de não produzir leite suficiente, ou ainda, de que o leite é fraco. Não existe leite fraco ou mama sem bico, existem sim, mamas que não foram estimuladas para a amamentação, e isso traz implicações, pois o bebê terá dificuldades de fazer a pega, mas mesmos assim, se as mulheres forem bem orientadas, ainda há solução. A mãe auxiliada se tranquiliza e o bebê aprende a sugar e ajustar a velocidade da sucção. ${ }^{11}$

Nesse sentido, a Lei no 8069/1990 (Estatuto da Criança e do Adolescente), em seu Artigo 9² diz: "O poder público, as instituições e os empregadores propiciarão condições adequadas ao aleitamento materno, inclusive aos filhos de mães sub-
Todavia, outras

mães anulam

esse momento

porque precisam

trabalhar e não têm

como amamentar

o seu bebê

devido a diversas

circunstâncias,

como por exemplo,

a distância entre o

trabalho e as suas

casas e ainda, por

falta de recursos

financeiros, ausência

de apoio familiar ou

da própria empresa

onde trabalha. metidas a medida privativa de liberdade" (BRASIL, 1990). ${ }^{12}$

Diante disso, como podemos ver, é assegurado a todas as mães o direito de amamentar seus filhos. Seja no ambiente de trabalho, em sua casa ou até mesmo, quando estão por algum motivo, privadas de sua liberdade, têm o direito de alimentar o seu bebê sem serem interrompidas, constrangidas ou incomodadas.

Assegurar e incentivar a amamentação - dever da Família, Sociedade e do Estado

O artigo na 227 da Constituição Federal de 1988 garante que é "dever da família, da sociedade e do Estado assegurar à criança, ao adolescente e ao jovem, com absoluta prioridade, o direito à vida, à saúde, à alimentação (...)”. (BRASIL, 1988). ${ }^{13}$

Muitas mães, por vezes, escolhem não amamentar, por acreditar fielmente em mitos populares como: o seio vai cair ou vai ficar fraca e impossibilitada de fazer outras atividades. Todavia, outras mães anulam esse momento porque precisam trabalhar e não têm como amamentar o seu bebê devido a diversas circunstâncias, como por exemplo, a distância entre o trabalho e as suas casas e ainda, por falta de recursos financeiros, ausência de apoio familiar ou da própria empresa onde trabalha. Se for uma empresa de pequeno porte, as dificuldades só aumentam, pois não há obrigatoriedade legal, e o patrão, por vezes, visa somente o lucro. Com vistas a isso, Marx (2004) afirma:

À medida que diminui o número de mulheres, mães trabalhadoras no mercado de trabalho, à medida que eles usurpam e monopolizam todas as vantagens deste período de evolução social, cresce a miséria, a opressão, a escravidão, a exploração. "A apropriação do trabalho e a centralização de seus recursos materiais chegaram a um ponto em que este invólucro se partirá em estilhaços" (MARX, 2004, p. 97-98). ${ }^{14}$

Nesse sentido, muitos patrões preferem contratar trabalhadores do sexo masculino, levando em conta que a mulher pode ter o período de gravidez, e precisará se afastar, e ainda seguido do período da amamentação, 
direito a ela garantido em Lei.

Pesquisas apontam que o índice de aleitamento materno (exclusivo) até seis meses, no Brasil, está em 39\%. A média de amamentação no país mostra que, dificilmente, as mães completam dois meses, quando o necessário seriam seis meses de aleitamento exclusivo para o bebê. Esses dados são resultados lamentáveis da ausência de políticas públicas que assegurem os direitos das mulheres trabalhadoras, seja junto às empresas de pequenos ou grandes portes ou através de recursos básicos como: falta de contratação, por parte do Estado, de mais profissionais na área da saúde, e assim poder oferecer formação continuada a esses profissionais visando possibilitar atendimento a gestantes sobre aleitamento e seus benefícios.

É necessário dizer que em postos de saúde os profissionais da área devido à sobrecarga de trabalho e à falta de servidores, muitas vezes, não conseguem formar grupos de gestantes para passar os devidos esclarecimentos sobre os procedimentos necessários para a amamentação à futura mãe.

A falta de incentivo e recursos dos próprios familiares, quando essa mãe necessita voltar ao trabalho ao término sua licença-maternidade, pois muitas delas não têm quem as ajude, ou quem assuma a responsabilidade em levar e trazer o bebê todos os dias até o seu local de trabalho para que ela possa alimentar o seu bebê, sem se preocupar com o deslocamento ou a distância entre o trabalho e sua casa, é certamente um dos maiores fatores de abandono do aleitamento materno a seus bebês.

Escutamos a todo o momento nas redes sociais as indústrias que produzem alimentos complementares transmitindo diversos fetiches e propagandas enganosas que reforçam a falsa informação de que o leite é fraco e a mãe precisa substitui-lo por produtos mais eficazes. Não existe leite fraco, o que existe na maioria das vezes, são mães com poucos recursos e sem informações, patrões gananciosos que não colaboram, e assim, no desespero e necessidade em manter o emprego para sobreviver, cortam o direito que a criança tem de ser amamentada.

\section{Detectou-se que a}

Consolidação das

Leis Trabalhistas

(CLT) exige

das empresas

que empregam

mais de 30 mães

trabalhadoras com

idade acima de 16

anos, a manutenção

de uma sala

exclusiva de apoio à

\section{amamentação.}

Como bem nos asseguram Souza e Rodrigues (2010, p. 38): “A consolidação da mulher no mercado de trabalho se revela na constante ampliação das taxas de participação feminina em todas as idades elevando assim, o peso da mulher na força de trabalho".15 Essa realidade requer empresas bem preparadas para atender de forma coerente todas as mães que queiram amamentar os seus filhos, sem serem prejudicadas, mas antes incentivadas e auxiliadas em tudo que for preciso para que se sintam seguras e bem a cada amamentação e assim evitar e, quem sabe, erradicar o desmame precoce.

\section{RESULTADOS E DISCUSSÃO}

Detectou-se que a Consolidação das Leis Trabalhistas (CLT) exige das empresas que empregam mais de 30 mães trabalhadoras com idade acima de 16 anos, a manutenção de uma sala exclusiva de apoio à amamentação. As mães que residem distantes do seu local de trabalho ou da creche onde deixam o seu bebê, enfrentam muitos desafios para seguir amamentando, e por isso, muitas delas necessitam abandonar a amamentação. Entretanto, diversos fatores podem contribuir para que o abandono da amamentação aconteça, pois ainda que amamentar os filhos se apresente como uma característica natural da espécie humana, na contemporaneidade, e, em uma sociedade capitalista, amamentar os filhos configura-se em uma prática social pouco estruturada e muito complexa, e, entre elas está a falta de cumprimento pelas empresas do " $\$ 1^{\circ}$ do art. 389 da CLT, e do art. 396 (BRASIL, 2016), ${ }^{16}$ que as obriga a flexibilizar o horário de trabalho da mãe. Além disso, faz-se necessária uma revisão séria da política de funcionamento de empresas com menos de 30 funcionários quanto à prática do aleitamento materno, pois muitas delas obrigam as mães que necessitam manter o seu emprego, a introduzir alimentos complementares antes dos seis meses, um dos principais fatores para o rompimento da amamentação. Por outro lado, mães que insistem em dar o bico para acalmar a criança, também influenciam o bebê ao desmame precoce.

\section{CONCLUSÃO}

A amamentação é uma experiência carregada de afeto, de saúde e muito amor. É nesse momento que a relação entre mãe e filho se estabelece, vínculos são formados e a confiança é firmada. Os laços construídos através da amamentação acompanham a mãe e o filho(a) durante a vida toda. Logo, a 


\section{artigo}

Aleitamento materno: o desafio da mãe trabalhadora que amamenta em uma sociedade capitalista

amamentação é certamente o maior elo que pode existir entre mãe e filho(a).

O leite materno não é insuficiente ou fraco. Ele é puro, completo e rico em nutrientes, carregado de afeto e amor! Com efeito, quando o bebê chora, ele não quer só ser alimentado, quer acalento para se sentir em segurança.

Os resultados da pesquisa apontam que os empregadores que respeitam as Leis trabalhistas que beneficiam as mulheres, mães, e oferecem a elas local apropriado para a amamentação e a guarda de seus bebês, facilitam a amamentação de seus filhos, contam com funcionárias que apresentam menor número de faltas, demonstram maior interesse em desenvolver suas atividades e apresentam maior índice de produtividade, pois não precisam se preocupar com seus bebês doentes.

Por fim, empresas públicas e privadas que oferecem convênio de saúde e creches nos locais de trabalho, além de permitir a proximidade entre mãe e filho, incentivam e garantem a amamentação da criança por um maior período, ocasionando benefícios econômicos e sociais a todas as partes envolvidas.

\section{REFERÊNCIAS}

1. Monteiro JCD, Nakano AMS, Gomes FA. O aleitamento materno enquanto uma prática construída: reflexões acerca da evolução histórica da amamentação e desmame precoce no Brasil. Invest Educ Enferm. 2011;29(2): 315 - 321.

2. Parizoto GM, Parada CM, Venâncio SI, Carvalhaes MA. Trends and patterns of exclusive breastfeeding for under-6-month-old children. J Pediatr (Rio J). 2009;85(3):201-208.

3. REA, Marina Ferreira, Possibilidades e limitações da amamentação entre mulheres trabalhadoras formais. Rev. Saúde Pública, 31 (2): 149-56, 1997.

4. BRASIL. Projeto de Lei No, de 2016 (Do Sr. Luiz Lauro Filho): Altera o art. 396 da Consolidação das Leis do Trabalho, aprovada pelo Decreto-lei $n^{\circ} 5.452$, de $1^{\circ}$ de maio de 1943 , para dispor sobre a redução da jornada da mãe lactante. Câmara dos Deputados, SANTA CATARINA, 2016. p. 1-4. Disponível em: https://www.camara.leg.br/proposicoesWeb/prop_mostrarintegra?codteor=1449898\#: : text=vida\%20do\%20beb\%C3\%AA.,0\%20art.,de\%20meia\%20hora\%20cada\%20um. Acesso em: 17 ago. 2020.

5. BRASIL. Projeto de Lei $N^{\circ}$, de 2016 (Do Sr. Luiz Lauro Filho): Altera o art. 396 da Consolidação das Leis do Trabalho, aprovada pelo Decreto-lei $n^{\circ} 5.452$, de $1^{\circ}$ de maio de 1943 , para dispor sobre a redução da jornada da mãe lactante. Câmara dos Deputados, SANTA CATARINA, 2016. p. 1-4. Disponivel em: https://www.camara.leg.br/proposicoesWeb/prop_mostrarintegra?codteor=1449898\#: : :text=vida\%20do\%20beb\%C3\%AA.,0\%20art.,de\%20meia\%20hora\%20cada\%20um. Acesso em: 17 ago. 2020.

6. DEMITTO, Marcela de Oliveira. BERCINI, Luciana Olga. ROSSI, Robson Marcelo. USO DE CHUPETA E ALEITAMENTO MATERNO EXCLUSIVO. Esc Anna Nery (impr.), Rio de Janeiro, v. 17, n. 2, p. 271-276, 2013. Disponivel em: https://www.scielo.br/pdf/ean/ v17n2/v17n2a10.pdf. Acesso em: 25 julh. 2020.

7. Fernandes VMB, Santos EKA, Erdmann AL, Pires DEP, Zampieri MFM, Gregório VRP. Implantação de salas de apoio à amamentação em empresas públicas e privadas: potencialidades e dificuldades. Rev. Gaúcha Enferm. 2016;37(esp):e2016-0046. doi: http://dx.doi.org/10.1590/1983- 1447.2016.esp.2016-0046.

8. GIL, Antônio Carlos. Como Elaborar Projetos de Pesquisa. 4. ed. São Paulo: Atlas, 2002.

9. RICHARDSON, R. J. Pesquisa social: métodos e técnicas. São
Paulo: Atlas, 2008.

10. BRASIL. Lei $n^{\circ} 13.436$, de 12 de abril de 2017: Altera a Lei $n^{\circ}$ 8.069, de 13 de julho de 1990 (Estatuto da Criança e do Adolescente), para garantir o direito a acompanhamento e orientação à mãe com relação à amamentação. Brasília, DF: Presidência da República, 2017. Disponível em: http://www.planalto.gov.br/ ccivil_03/_Ato2015-2018/2017/Lei/L13436.htm. Acesso em: 16 ago. 2020.

11. BRASIL. Lei $n^{\circ} 13.436$, de 12 de abril de 2017: Altera a Lei ${ }^{\circ}$ 8.069, de 13 de julho de 1990 (Estatuto da Criança e do Adolescente), para garantir o direito a acompanhamento e orientação à mãe com relação à amamentação. Brasília, DF: Presidência da República, 2017. Disponível em: http://www.planalto.gov.br/ ccivil_03/_Ato2015-2018/2017/Lei/L13436.htm. Acesso em: 16 ago. 2020.

12. BRASIL. Lei $n^{\circ} 8.069$, de 13 de julho de 1990. Dispõe sobre o Estatuto da Criança e do Adolescente e dá outras providências. Brasília, DF: Presidência da República, 1990. Disponível em: http://www.planalto.gov.br/ccivil_03/leis/l8069.htm. Acesso em: 14 ago. 2020.

13. BRASIL. Constituição da República Federativa do Brasil, de 5 de outubro de 1988. Brasília: Senado Federal, 1988. Disponível em: http://www.planalto.gov.br/ccivil_03/constituicao/constituicao.htm. Acesso em: 25 de ago. 2020.

14. MARX, Karl. A origem do Capital. São Paulo: Centauro, 2004. $116 p$.

15. SOUZA, Marilei de M. Tavares e. RODRIGUES, Lilia Marques Simões. Desafios da Mulher Trabalhadora diante Amamentação. Revista Pró-Universus, Vassouras - Rio de Janeiro, v. 1, n. 1, p. 33-42, 2010. Disponivel em: http://editora.universidadedevassouras.edu.br/index.php/RPU/article/view/318. Acesso em: 1 ago. 2020.

16. BRASIL. Projeto de Lei $N^{\circ}$, de 2016 (Do Sr. Luiz Lauro Filho): Altera o art. 396 da Consolidação das Leis do Trabalho, aprovada pelo Decreto-lei $n^{\circ} 5.452$, de $1^{\circ}$ de maio de 1943, para dispor sobre a redução da jornada da mãe lactante. Câmara dos Deputados, SANTA CATARINA, 2016. p. 1-4. Disponivel em: https://www.camara.leg.br/proposicoesWeb/prop_mostrarintegra?codteor=1449898\#: : text=vida\%20do\%20beb\%C3\%AA.,0\%20art.,de\%20meia\%20hora\%20cada\%20um. Acesso em: 17 ago. 2020. 